\title{
A therapeutic group program in an aged person's mental health unit
}

\author{
Angela Ferris ${ }^{1}$, Kuruvilla George ${ }^{2}$ \\ ${ }^{1}$ Senior Occupational Therapist, Aged Person's Mental Health, Eastern Health, Victoria, Australia \\ ${ }^{2}$ Director, Aged Person's Mental Health, Eastern Health, Victoria, Australia \\ Clinical Professor, Deakin University, Clinical Associate Professor, Monash University \\ *Corresponding author E-mail: kuruvilla.george@easternhealth.org.au
}

\begin{abstract}
Objective: The aim of this paper is to describe a therapeutic group program in an acute aged person's mental health inpatient unit. The setting of the unit, the development of the program and patient feedback are discussed.

Conclusion: The key factor in the success of the group program was the support of the multidisciplinary staff facilitators of the program. An ongoing and significant challenge is the provision of groups appropriate for the varying levels of function within the patient group and especially meeting the needs of patients with behavioural and psychological symptoms of dementia
\end{abstract}

\section{Introduction}

Group therapy is a process that contributes to improvement in the client's condition using actions of the therapist, the other members of the group, and the client [1]. It is generally regarded as an effective treatment modality in acute psychiatric settings [2]. The interrelationships and personal interactions create the potential for therapeutic change [3]. Occupational therapists use a variety of group situations to enhance the curative or therapeutic opportunities that groups offer [4]. Elderly mentally ill people should be viewed just like any other client groups, with meaningful activities used in order to facilitate growth and change and to ensure that existing skills are maintained for as long as possible [5]. Authors addressing the requirements of elderly people suggest that their desire to participate in meaningful activities is equally as great as that of their younger counterparts, [6] so age or disability should provide no barrier to the use of activity as therapy. Fortune and Fitzgerald [7] recommend that if an occupational milieu is to be established in inpatient settings, team-wide strategies that serve to build partnerships between disciplines need to be implemented.

This paper describes such a therapeutic group program in an acute aged person's mental health inpatient unit.

\section{The setting}

The Eastern Health Aged Person's Mental Health Acute Inpatient Unit (South Ward), is located within the Peter James Centre which is a subacute campus in the eastern suburbs of Melbourne. The unit has 30 beds and is primarily for patients over 65 years old with a long-standing mental illness, or who have developed functional illnesses such as depression and psychosis in later life. Patients experiencing severe behavioural and psychological symptoms associated with organic disorders such as dementia are also cared for on South Ward. It serves a catchment population of 110,000 persons 65 years and over. South Ward is the largest acute aged person's mental health inpatient unit in Victoria.

The group program was developed to increase the social, occupational and psychological functioning of the patients through the use of educational, recreational and skills based experiences. A group program could add to the therapeutic milieu of the ward by providing structure and stimulation, while increasing the opportunities for positive and therapeutic interactions between patients and staff. The group program currently runs each weekday. The program is coordinated by the occupational therapist, with a multidisciplinary team acting as facilitators. The daily structure of the program is overseen by the allied health assistant who co-facilitates groups with the allied health professionals, and facilitates the recreational components of the program. 
Table 1: (Therapeutic Group Program)

\begin{tabular}{|c|c|c|c|c|c|}
\hline & Therapeutic & Group & $28^{\text {th }}$ Feb & \multicolumn{2}{|c|}{ 4th March 2011} \\
\hline Time & $\begin{array}{l}\text { Monday } \\
\text { 28th }\end{array}$ & $\begin{array}{c}\text { Tuesday } \\
\text { 1st }\end{array}$ & $\begin{array}{l}\text { Wednesday } \\
\text { 2nd }\end{array}$ & $\begin{array}{c}\text { Thursday } \\
\text { 3rd }\end{array}$ & $\begin{array}{c}\text { Friday } \\
\text { 4th }\end{array}$ \\
\hline $8.00 \mathrm{am}$ & & $\begin{array}{l}\text { (Day Hospital in } \\
\text { activities room) }\end{array}$ & $\begin{array}{l}\text { Breakfast Group } \\
\& \text { Angela \& Rachelle }\end{array}$ & $\begin{array}{l}\text { Breakfast Group } \\
\mathbb{2} \text { Angela \& Rachelle }\end{array}$ & \\
\hline $8.30 \mathrm{am}$ & Breakfast & Breakfast & Breakfast & Breakfast & Breakfast \\
\hline $9.45 \mathrm{am}$ & $\begin{array}{c}\text { Community } \\
\text { Meeting } \\
\text { Angela + Prue }\end{array}$ & $\begin{array}{l}\text { Exercise Group } \\
\text { Prue \& Rachelle }\end{array}$ & $\begin{array}{c}\text { Exercise Group } \\
\text { Rachelle }\end{array}$ & $\begin{array}{c}\text { Exercise Group } \\
\text { Rachelle }\end{array}$ & $\begin{array}{c}\text { Exercise Group } \\
\text { Rachelle }\end{array}$ \\
\hline $10.30 \mathrm{am}$ & Morning Tea & Morning Tea & Morning Tea & Morning Tea & Morning Tea \\
\hline $11.00 \mathrm{am}$ & $\begin{array}{l}\text { Mental Health } \\
\text { Matters } \\
\text { Hema + Angela }\end{array}$ & Gardening & $\begin{array}{c}\text { Patient Info } \\
\text { Session } \\
\text { Dietitian } \\
\text { Rhonda }\end{array}$ & Church Service & $\begin{array}{c}\text { Social } \\
\text { Communication } \\
\text { Emma + Rachelle }\end{array}$ \\
\hline $12.00 \mathrm{pm}$ & Lunch & Lunch & Lunch & Lunch & Lunch \\
\hline $1.00 \mathrm{pm}$ & $\begin{array}{l}\text { Exercise Group } \\
\qquad \begin{array}{c}\text { Prue } \\
\text { Pry }\end{array}\end{array}$ & $\begin{array}{l}\text { (AH Staff at education) } \\
\text { Movie in North } \\
\text { Lounge } \\
\text { Rachelle to setup before } \\
1 \mathrm{pm}\end{array}$ & $\begin{array}{c}\text { Recreation in } \\
\text { activities room } \\
\text { Rachelle }\end{array}$ & Relaxation & $\begin{array}{c}\text { Recreation in } \\
\text { activities } \\
\text { room } \\
\text { Rachelle }\end{array}$ \\
\hline $2.30 \mathrm{pm}$ & Afternoon Tea & Afternoon Tea & Afternoon Tea & Afternoon Tea & Afternoon Tea \\
\hline $3.00 \mathrm{pm}$ & $\begin{array}{l}\text { Activities room open } \\
\text { Free time! } \\
\text { Angela to setup }\end{array}$ & $\begin{array}{l}\text { Walking Group } \\
\text { Rachelle + Prue or a nurse }\end{array}$ & Cafe Visit & Sing A Long & John \& Rachelle \\
\hline $5.00 \mathrm{pm}$ & Dinner & Dinner & Dinner & Dinner & Dinner \\
\hline
\end{tabular}

Highlights of the program include:

1. Community Meetings - held weekly to provide a structured opportunity for communication between staff and patients. Information about the ward is provided in the form of a quiz. Patients are provided with an orientation to the group program, and encouraged to give feedback and ask questions about the ward.

2. Mental Health Matters - these weekly sessions are facilitated by the clinical psychologist and psychology intern. The group themes change according to the needs of the patients. Topics include: problem solving, anxiety, depression, positive ageing, goal setting and sleep hygiene.

3. Breakfast Group - this group runs twice weekly and is aimed at patients who are planning to return to independent living. The group provides an informal opportunity for the occupational therapist to assess patients light meal preparation skills.

4. Patient Information Sessions - the group runs weekly and currently includes the dietitian providing fortnightly information sessions, with alternate weeks filled by various clinicians. Dietitian includes: healthy eating, food hygiene and meal planning. The alternate weeks have included: the benefits of exercise (physiotherapist), falls prevention at home (occupational therapist), and community services (social work).

5. Delta Dogs - our volunteer Maggie and her dog Bella visit the ward on a fortnightly basis for one hour. The visits have been particularly beneficial for patients with depression and dementia.

6. John's Toolbox - facilitated by a nurse, this weekly discussion group focuses on tools for recovery including positive thinking and attitudes. 
7. Social Communication - a structured discussion group facilitated by the speech pathologist that encourages social interaction amongst the patients. The group uses reminiscence as a key component of the sessions to facilitate the participation of patients with dementia.

8. Exercise Group - facilitated by the physiotherapist and allied health assistant, this daily group provides both practical experiences and education relevant to the patients' age group.

The group program includes many other opportunities including walking, gardening, art and craft, relaxation, current affairs discussions and sing-a-longs.

\section{Patient recruitment}

The group program is promoted to ensure all patients are informed and encouraged to participate. Orientation to the program is provided during the weekly community meeting. Individual orientation is provided as needed by group program staff. A program whiteboard is on display in the main ward foyer, with further group flyers displayed in both the ward corridor and activities room. Participation is also encouraged before the commencement of each group.

Table 2: (Group Attendance data for the year 2011)

\begin{tabular}{|c|c|c|c|c|c|c|c|c|c|c|c|c|}
\hline & Jan & Feb & Mar & Apr & May & Jun & Jul & Aug & Sep & Oct & Nov & Dec \\
\hline Groups facilitated & 66 & 75 & 90 & 71 & 87 & 92 & 85 & 88 & 93 & 72 & 83 & 78 \\
\hline Group program days & 19 & 20 & 23 & 18 & 21 & 21 & 21 & 23 & 22 & 19 & 22 & 20 \\
\hline Average groups per day & 3.5 & 3.75 & 3.9 & 3.9 & 4.1 & 4.4 & 4.0 & 3.82 & 4.2 & 3.8 & 3.8 & 3.9 \\
\hline Attendances per month & 467 & 488 & 663 & 473 & 665 & 798 & 545 & 592 & 724 & 454 & 592 & 448 \\
\hline Attendances per day & 24.5 & 24.4 & 28.8 & 26.3 & 31.7 & 38 & 26 & 25.7 & 32.9 & 23.9 & 26.9 & 22.4 \\
\hline $\begin{array}{l}\text { Average attendances per } \\
\text { group }\end{array}$ & 7 & 6.5 & 7.4 & 6.7 & 7.6 & 8.7 & 6.4 & 6.73 & 7.8 & 6.3 & 7.1 & 5.7 \\
\hline $\begin{array}{l}\text { Average patients on ward } \\
\text { per month }\end{array}$ & 24.2 & 23.1 & 18.4 & 19.1 & 22.0 & 25.9 & 18.6 & 22.8 & 25 & 20.7 & 24.2 & 20.2 \\
\hline $\begin{array}{l}\text { Range of attendance total } \\
\text { per group }\end{array}$ & $1-20$ & $1-15$ & $1-16$ & $1-16$ & $2-17$ & $2-19$ & $1-16$ & $2-17$ & $1-15$ & $1-14$ & $1-19$ & $1-12$ \\
\hline $\begin{array}{l}\text { Percentage of patients } \\
\text { attending each group }\end{array}$ & $29 \%$ & $28 \%$ & $40 \%$ & $35 \%$ & $34 \%$ & $33 \%$ & $34 \%$ & $29.5 \%$ & $31 \%$ & $30.4 \%$ & $29.3 \%$ & $28.2 \%$ \\
\hline
\end{tabular}

Groups facilitated: The total number of groups run during the month

Group program days: Number of days the group program was run (e.g. normal working weekdays)

Average groups per day: Total groups divided by number of group days

Attendances per month: Total attendance of all groups for the month

Attendances per day: Total attendances per month divided by group program days

Average attendances per group: Total attendances per month divided by groups facilitated

Average patients on ward per month: Statistic provided by ward clerk

Range of attendance total per group: Smallest attendance and largest attendance at a single group run during the month

When considering patient attendance figures it is important to note that many groups are designed to meet the needs of specific diagnoses. For example, patients with severe dementia are not targeted to attend psycho-education groups. Patients can usually be categorised between unable to participate, potentially able to participate with support and able to participate independently. Anecdotal evidence on south ward suggests $20 \%$ are usually unable to participate, $30 \%$ are able to participate with support, and $50 \%$ are usually able to participate independently. Therefore of the patients targeted for any group (50-80\% of the ward), attendances on average are approximately $40 \%$.

\section{Patient feedback}

Verbal and written feedback is collected. Patients are encouraged to provide feedback during the community meeting. A written survey is completed by patients before discharge, providing ideas for improvement. Recent feedback received includes:

1. Request for more groups - Patients requested more gardening, musical afternoons and DVD's, fun activities, interaction, and visits by our pet therapy volunteer. 
2. Positive Feedback - Patients suggested the groups were 'good' and easy to follow and that the program was well rounded. Two patients suggested the program was useful for 'waking up'. Highlights of the program were listed as relaxation and breakfast group.

3. Socialisation - Patients reported the most enjoyable aspects of the program as sharing ideas with other patients, mixing with other patients, conversation and growing to understand co-patients.

4. Suggestions for improvement - Patients' suggestions for improvement were mainly around strategies for including more patients in the groups. They made suggestions to include specific activities for patients with dementia.

The surveys are reviewed monthly by the occupational therapist, and adjustments are made in response to the feedback. Changes include: commencing a movie afternoon, re-organising the ward CD and DVD collections, purchasing additional gardening supplies and working to create a sustainable space for the weekly gardening group. We have finalised an agreement with the PJC chaplain to provide a monthly religious service in the ward.

\section{Discussion}

The key factor in the success of the group program was the support of the multidisciplinary staff facilitators of the program. Sharing the load of the program between many facilitators made the program more sustainable and flexible. Endeavouring to have two staff facilitate all educational and skills based groups further sustained the program. Commencing the program had a significant effect on the day to day running of the ward. Patients were increasingly occupied in groups and not readily available for other procedures and appointments. Communication systems were put in place to ensure patients, facilitators, visitors and nursing staff were all appropriately informed of patients' whereabouts.

The ward had many visible spaces for groups to run, however when trialled they were often too busy and noisy. In comparison, the large activity room was quiet and well received by patients. A balance between groups in highly visible areas and the activities room has been achieved. Highly visible areas are useful for patient recruitment, while the activities room is a drawcard for patients needing a quieter space. One significant factor in environmental success was to reclaim the activities room for the exclusive use of patients instead of for staff meetings and training.

Resources for the group program have been readily available. The ward manager encouraged and prioritised staff participation in the group program. Initially weekly meetings were held between the manager and facilitators to provide support and review of the progress of the program.

Recruiting and retaining patients in the program has been successful, as evidenced by the earlier statistics. This achievement has relied on supportive, approachable members of staff that are able to engage the patients. Success has been found by providing initial introductions to the program and gradually increasing the amount of encouragement given to each patient over the course of the admission.

An ongoing and significant challenge is the provision of groups appropriate for the varying levels of function within our patient group. A divide between functional illness and dementia patients is routinely observed, however continues to be addressed by facilitators. Patients as a whole have been observed to be the best at motivating and encouraging each other to attend the groups.

The primary goal is to maintain the current quality and quantity of groups, while continuing to adjust and improve the program according to needs identified. Increasing the number of patients attending is less of a priority. Patient feedback is considered most valuable, and efforts will be made to ensure all capable patients provide written feedback on discharge. Future goals include increasing activity and recreation out of hours and on weekends as well as encouraging increased nursing and medical staff participation. A trial of the Sensory Connections Program ${ }^{8}$ is currently underway, with plans to develop a sensory room project. Strategies to better meet the occupational and recreational needs of dementia patients are a constant challenge.

\section{References}

[1] Bloch S, Crouch E, Relbstein J. Therapeutic factors in group therapy. Archives of General Psychiatry 1981, 38 519-526

[2] Yalom I. The theory and practice of group psychotherapy. 3rd edition, New York, Basic Books, 1985

[3] Stein F, Tallant B. Applying the group process to psychiatric occupational therapy Part 2: a model for a therapeutic group in psychiatric occupational therapy. Occupational Therapy in Mental Health, 1988, 8, 29-51

[4] Finlay L. Groupwork in occupational therapy. London, Chapman and Hall, 1993

[5] Challis T. Purposeful activity and elderly mentally ill people: Why? British Journal of Occupational therapy 1996, 59(4), 183-184

[6] Green S. Elderly mentally ill people and quality of life, who wants activities? British Journal of Occupational Therapy 1995, 58(9), 377-382 
[7] Fortune $\mathrm{T}$ and Fitzgerald $\mathrm{H}$. The challenge of interdisciplinary collaboration in acute psychiatry: Impacts on the occupational milieu. Australian Occupational Therapy Journal 2009, 56, 81-88

[8] Moore K. The Sensory Connection Program. 2005, Framington, MA: Therapro. 